\title{
NOVATOS MOTIVADOS E VETERANOS ACOMODADOS: REPRESENTAÇÕES SOCIAIS DE TÉCNICOS- ADMINISTRATIVOS SOBRE A ATUAÇÃO NO TRABALHO
}

\begin{abstract}
RESUMO
Em um cenário de expansão das universidades públicas federais, cresce o número de estudantes, docentes e técnicos-administrativos, demandando uma compreensão mais ampla das interações que emergem na dinâmica social de uma universidade. De modo geral, as pesquisas realizadas no âmbito universitário dirigem sua atenção para os discentes e docentes, sendo raros os estudos que têm como foco aqueles que lidam com a área administrativa. Neste artigo, nosso objetivo é descrever e analisar os conteúdos e a estrutura das representações sociais dos técnicos-administrativos em educação da Universidade Federal de Uberlândia em relação à atuação no trabalho de veteranos e novatos. Para tanto, realizamos uma pesquisa de natureza qualitativa, com entrevistas semiestruturadas aplicadas a oito técnicosadministrativos em educação que trabalham na Universidade Federal de Uberlândia, sendo seus conteúdos analisados com base na análise do discurso. Como resultados, identificamos que os veteranos constroem suas representações sobre a atuação dos novatos como motivados pelo início de carreira, enquanto que os novatos constroem suas representações sociais sobre os veteranos como acomodados por estarem já próximos da aposentadoria.
\end{abstract}

Palavras-chave: Representação social, técnicos-administrativos, Universidade Federal de Uberlândia

\section{BEGINNERS MOTIVATED AND ACCOMMODATED VETERANS: SOCIAL REPRESENTATIONS OF TECHNICAL- ADMINISTRATIVES ABOUT THE PERFORMANCE AT WORK}

\section{ABSTRACT}

In a scenario of expansion of federal public universities, the number of students, teachers and technical-administrative grows, requiring a broader understanding of the interactions that emerge in the social dynamics of a university. Overall, researches carried out in universities direct their attention to the students and teachers, with few studies that focus on those who deal with the administrative area. In this article, we aim to describe and analyze the contents and the structure of social representations of the technical-administrative in education at the Federal University of Uberlândia related to activities in the work of veterans and novices. To this end, we conducted a qualitative study with semi-structured interviews applied to eight

\footnotetext{
1 Mestrando em Administração do Programa de Pós-Graduação em Administração da Universidade Federal de Uberlândia (ecarmo85@gmail.com)

2 Doutora em Administração de Empresas - EAESP/FGV e Professor da Universidade Federal de Uberlândia (cintia@fagen.ufu.br)

3 Doutor em Ciências Sociais (Sociologia) - PUC/SP e professor da Universidade Federal de Uberlândia. (eduardo.loebel@fagen.ufu.br)
} 
technical-administrativein education working at the Federal University of Uberlândia, and its contents were analyzed based on discourse analysis. As a result, we found that veterans build their representations about the performance of novice and motivated by early-stage, while the newcomers build their social representations of veterans like accommodated because they are already nearing retirement.

Keywords: Social representation, administrative technicians, Federal University of Uberlândia

\section{INTRODUÇÃO}

O ensino superior no Brasil passou por diversas mudanças nas últimas décadas que se refletem em sua estrutura atual. Um dos marcos dessas alterações foi a Lei de Diretrizes e Bases (LDB), em 1996 (KAMPF,2013). De acordo com relatório emitido pela PROREH (2013), além da elevada participação de instituições privadas - considerado como traço histórico -, o ensino passou por inovações como, por exemplo, as formas de acesso aos segmentos de baixa renda e as avaliações.

No caso específico das universidades federais, o relatório baseado em informações disponibilizadas no site do MEC afirma que a expressiva expansão destas universidades se deve ao REUNI e ao Programa de Expansão Fase I. De acordo com o MEC (2104), a expansão da educação superior federa iniciou-se em 2003 com a criação de diversos campi no interior do país, na forma de campus avançado. Nessa fase, o número de municípios que sediam universidades federais passou de 114 para 237, no final de 2011.

Em meio à expansão da rede federal de ensino, o Governo buscou, a partir da organização de um conjunto de ações, estruturar uma política nacional de recursos humanos. Assim, em 2006, instituiu-se a "Política Nacional de Desenvolvimento de Pessoal" por meio do Decreto 5.707, cujo objetivo é o de estabelecer uma política de capacitação permanente dos servidores; definiram-se diretrizes gerais do sistema de avaliação de desempenho; foram estruturadas/ criadas carreiras e tabelas remuneratórias (com destaque para as modificações introduzidas nas carreiras dos Técnicos Administrativos em Educação e Docentes do magistério superior), entre outras medidas.

A expansão criou novos cursos, ampliando o número de estudantes e, consequentemente, demandou a contratação de novos docentes e técnicos-administrativos, um movimento que mudou a dinâmica social das universidades federais, depois de oito anos sem concursos públicos. Esse movimento resultou na interação entre um contingente significativo de novatos e veteranos no mesmo espaço social, dando novos contornos no cotidiano organizacional. As pesquisas realizadas no âmbito universitário dirigem sua atenção para os discentes e docentes, sendo raros os estudos que têm como foco aqueles que lidam com a área administrativa.

Desse modo, conhecer as representações sociais dos técnicos-administrativos em educação contribui para o conhecimento formado sobre esses atores e sobre o modo pelo qual eles constroem as imagens sobre si mesmos e sobre os outros. Conforme Jodelet (2001), as representações sociais são fenômenos complexos presentes na vida social, seja nos discursos, mensagens, imagens, valores e atitudes. Portanto, um caminho para entender a dinâmica social é analisar as representações sociais que nela atuam. O corpo de técnicosadministrativos tem estado em uma posição periférica em pesquisas, as quais colocam no centro o corpo discente e docente. No entanto, os técnicos-administrativos em educação (TAEs) desempenham funções que atravessam todos os níveis de gestão das IES, interagindo com a comunidade acadêmica cotidianamente.

Diante deste panorama de ampliação e renovação dos recursos humanos, este trabalho tem como objetivo descrever e analisar os conteúdos e a estrutura das representações 
sociais dos técnicos-administrativos em educação da Universidade Federal de Uberlândia em relação à atuação no trabalho de veteranos e novatos. É uma pesquisa qualitativa com aplicação de entrevistas semiestruturadas a oito técnico-administrativos, com o objetivo de identificar as representações de dois grupos: ingressantes na carreira na Universidade e estão em atividade por no máximo 3 anos - ou seja, em estágio probatório; e aqueles cujo tempo de serviço os permitem o direito de aposentar-se. As técnicas para coleta e análise das informações pautaram-se na evocação livre e na análise do discurso. A pesquisa foi realizada nos meses de junho e julho de 2014.

O artigo está estruturado nas seguintes seções: esta introdução com uma breve contextualização; a revisão da literatura sobre representações sociais; os procedimentos metodológicos; os resultados encontrados e as considerações finais.

\section{REPRESENTAÇÕES SOCIAIS}

Não existe uma única definição de representações sociais, porém, neste trabalho, utilizase a abordagem do conceito segundo a construção teórica de Serge Moscovici, pertencente à corrente francesa da psicologia social. Segundo Marques, Oliveira e Gomes (2004), o autor evitou adotar uma única definição para o tema com o objetivo de evitar o fechamento precoce do conceito. Moscovici afirma que, por representações sociais, "entendemos um conjunto de conceitos, proposições e explicações originadas na vida cotidiana do curso de comunicações interpessoais"[...] (MOSCOVICI, 1978, p.181)

A representação social é a construção mental da realidade que permite a compreensão e organização do mundo, bem como é a que orienta o comportamento (MOSCOVICI, 1978). Segundo Garcia (1997), a bagagem histórica, tanto social como pessoal do indivíduo e as informações capitadas são capazes de formar os elementos da realidade, os conceitos, as teorias e as práticas, permitindo que se tornem compreensíveis e úteis. Nesse diapasão, as representações sociais "tornam um objeto significante, introduzindo-o num espaço comum, digerindo-o de forma a permitir sua compreensão e sua incorporação como recurso peculiar ao sujeito" (GARCIA, 1997, p.57).

São construções sócio-históricas resultantes do processo de socialização do sujeito e é por isso que segundo Correa et al (2007, p.193), Moscovici (1978) enfatiza por igual tanto a esfera social como a individual, ou seja, a representação é uma construção do sujeito enquanto sujeito social. Por isso, as representações de cada indivíduo refletem o grupo social a que ele pertence, que se justifica conforme seus interesses específicos (JOVCHELOVITCH,1995; MINAYO,1995). Deste modo, as representações são essencialmente fenômenos sociais que, mesmo sendo formas de conhecimento que se manifestam como elementos cognitivos, devem ser entendidos a partir do seu contexto de produção, uma vez que são resultados das condições em que surgem e circulam (SPINK, 1993).

As representações facilitam a aproximação da pessoa com a realidade externa, tornando-a mais perceptível a ela, quando esta, por exemplo, seleciona um objeto e o integra ao seu repertório pessoal, traduzindo algo significante ao indivíduo. Vale lembrar que esse objeto pode ser humano, social, material ou mesmo uma ideia que passa a ter uma existência real através da apropriação destes pelas representações sociais, consideradas uma forma de conhecimento do senso comum, elaborado e compartilhado socialmente. Segundo Spink (1993), as representações acontecem sempre de um sujeito para o objeto mas não são reproduções desse objeto e por isso são tidas como construções.

Segundo Jodelet (2001), o homem tem a necessidade de compreender o mundo que está em sua volta e isso o leva a criar representações que estão presentes nos discursos, palavras, mensagens, imagens cristalizadas em condutas e em organizações. Através dos 
mecanismos de ancoragem e objetivação, o indivíduo recria o objeto com a ilusão de que as coisas são aquilo que percebemos, o que faz com que a realidade seja vista de maneira única por cada pessoa.

Existe uma relação entre as representações e as práticas, uma vez que aquilo que pensamos depende daquilo que fazemos e vice-versa (ROUQUETTE, 1978); isto é, o sujeito constrói representações em coerência com a sua história e visão de mundo e capacidades. Diferentemente do que acontece com as representações (que derivam da prática), as práticas não são de livre escolha pelo sujeito já que existem pressões sociais que forçam o indivíduo a agir de certa maneira. Assim, a experiência da realidade faz com que as representações sejam revistas, situando as condutas como agentes transformadores das mesmas. Nesse sentido, Moscovici (1978, p. 49) afirma que a representação é uma "preparação para a ação" pois além de ela guiar o comportamento do indivíduo, ela "remodela e reconstitui os elementos do meio ambiente em que o comportamento deve ter lugar".

De acordo com Spink (1993, p.307), possivelmente, a contribuição mais valiosa da Psicologia Social para o estudo das representações sociais seria a "ênfase no processo de elaboração das representações a partir de práticas sociais que as definem e que são por elas definidas, bem como a abertura da possibilidade de se trabalhar o particular como expressão do universal, através de estudos de caso social e historicamente contextualizados". A definição de Spink para representações sociais está em acordo com a definição de Jodelet (2001), ou seja, a trata-se de um conhecimento prático orientado para a comunicação e compreensão da dinâmica social, material e ideativa, manifestando-se como elementos cognitivos através de conceitos e imagens.

Desse modo, as representações sociais contribuem para a elaboração de uma realidade comum, devendo, portanto, serem entendidas a partir do contexto em que foram produzidas. Nesse sentido, Spink (1993) observa que, ao se falar em representações sociais, é necessário definir o aspecto a ser considerado. Nessa direção, salientamos que este estudo trata das representações sociais de técnicos-administrativos quanto a atuação de veteranos e novatos em uma universidade pública federal, considerando as transformações pelas quais essas passaram, desde as duas últimas décadas. Assim, é na manifestação das representações sociais sobre a atuação dos novatos e veteranos no cotidiano organizacional da universidade que podemos perceber a concepção e imagens que caracterizam os dois grupos.

\section{Principais estudos nacionais sobre os técnicos-administrativos em educação}

O corpo técnico-administrativo em educação não é considerado um sujeito recorrente nas pesquisas em Administração. No campo da educação, Andriola e Souza (2010) analisaram as representações sociais de gestores e técnicos-administrativos da Universidade Federal do Ceará com o objetivo de analisar a cultura avaliativa, identificando que as representações desses sujeitos apresentam especificidades em relação à inserção social e aos interesses inerentes de cada segmento.

Na área de gestão pública, em sua a dissertação de mestrado, Cordeiro (2013) analisa o processo de avaliação de desempenho funcional dos TAE's da Universidade Federal de Pernambuco à luz da teoria das representações sociais, encontrando que apontam para a inadequação do processo de avaliação em relação à realidade dos servidores, e, consequentemente, para a necessidade de uma revisão do processo de avaliação com vistas ao aprimoramento.

Duarte, Ferreira e Lopes (2010) consideraram os técnicos-administrativos como sujeitos de pesquisa para investigar a aplicação do modelo de gestão por competências em uma organização pública, realizando um estudo de caso na Universidade Federal do Tocantins. 
Como resultados, os autores encontraram que a aplicação do modelo de gestão por competências pode proporcionar o suporte necessário para as ações de desenvolvimento e capacitação, constituindo-se em uma ferramenta para o desenvolvimento dos servidores e das organizações públicas.

Assim, uma vez apresentada a contextualização em que se insere e o tratamento dos aspectos teóricos relativos ao tema presente neste artigo, passa-se ao percurso metodológico do caso particular de estudo das representações sociais criadas por TAE's da Universidade Federal de Uberlândia e, posteriormente, à análise e conclusões a respeito do que fora encontrado.

\section{PROCEDIMENTOS METODOLÓGICOS}

Neste estudo, utilizou-se a Teoria das Representações Sociais, no contexto da psicologia social.Os métodos de coleta e análise das informações pautaram-se na análise de conteúdo temática (BARDIN, 1979) das entrevistas realizadas com os técnicos-administrativos. Segundo Moscovici (1978), para que a representação se diferencie da mera opinião formulada em um dado momento, mediante o estímulo do pesquisador, o contexto de formação da representação deve ser levado em consideração e é por isso que a pesquisa qualitativa e a técnica de análise de conteúdo se mostraram apropriadas para a abordagem dos aspectos relativos à representação.

Para a coleta de dados foram realizadas 8 entrevistas com TAE's em uma cidade do triângulo mineiro, nos meses de junho e julho de 2014. Os sujeitos são profissionais que trabalham na área administrativa hospitalar e secretarias de cursos de graduação e/ou pósgraduação na Universidade Federal de Uberlândia. Nesta organização, foram compostos dois grupos de entrevistados: um grupo de trabalhadores chamados "novatos", que corresponde àqueles cujo ingresso deu-se mediante concurso público e que se encontram no estágio probatório - que segundo a Lei 8.112/90 é de três anos; e o outro grupo formado por funcionários que já atingiram o tempo necessário ao pleito da aposentadoria por tempo de serviço - que segundo a Constituição Federal de 1988 é de 30 anos para as mulheres e de 35 para os homens - mas que ainda se encontram na ativa: foram chamados de "veteranos". Estipulou-se o número de 8 sujeitos para cada categoria.

Os dados obtidos nesta pesquisa foram colhidos por meio da utilização do método evocação livre e foram determinados previamente cinco indutores com a intenção de auxiliar a manifestação dos entrevistados, os quais se constituem nas categorias de análise: disciplina, iniciativa, responsabilidade, produtividade, assiduidade. Esses cinco elementos foram escolhidos por serem a maneira como os servidores em estágio probatório têm o seu desempenho avaliado e está previsto na própria lei dos servidores públicos federais (Lei 8112/90). Os resultados obtidos foram comparados entre os grupos e analisados de maneira qualitativa à luz do referencial teórico utilizado.

O perfil dos entrevistados foram funcionários administrativos de nível C e D da carreira (auxiliares e assistentes) da Universidade Federal de Uberlândia, em Uberlândia-Minas Gerais. Dentre os 4 funcionários, dois foram do sexo masculino e os outros seis do sexo feminino. Todos desempenhavam função administrativa: dois lotados no Hospital Odontológico, dois na Faculdade de Odontologia (FOUFU), dois no Hospital de Clínicas (HC), um na Faculdade de Ciências Contábeis (FACIC) e outro na Faculdade de Engenharia Mecânica (FEMEC). A maioria tinha título de graduação em ensino superior, com pós-graduação lato sensu em andamento. A idade dos entrevistados variou de 21 a 63 anos. A tabela abaixo ilustra o perfil dos entrevistados. 
Tabela 2 - Perfil dos entrevistados

\begin{tabular}{|c|c|c|c|c|c|}
\hline Entr. & Sexo & Idade & Escolaridade & Lotação & $\begin{array}{c}\text { Tempo de } \\
\text { exercício }\end{array}$ \\
\hline 1 & F & 24 & $\begin{array}{c}\text { Pós-graduação lato sensu } \\
\text { incompleta }\end{array}$ & FOUFU & 9 meses \\
\hline 2 & M & 21 & $\begin{array}{c}\text { Ensino Superior Incom- } \\
\text { pleto }\end{array}$ & HO & 5 meses \\
\hline 3 & M & 25 & $\begin{array}{c}\text { Pós-graduação lato sensu } \\
\text { incompleta }\end{array}$ & FEMEC & 2 anos \\
\hline 4 & F & 22 & $\begin{array}{c}\text { Pós-graduação lato sensu } \\
\text { incompleta }\end{array}$ & FACIC & 10 meses \\
\hline 5 & F & 55 & Pós-graduada & HO & 37 anos \\
\hline 6 & F & 63 & $2^{\circ}$ Grau Completo & HC & 37 anos \\
\hline 7 & F & 53 & Superior Incompleto & FOUFU & 32 anos \\
\hline 8 & F & 59 & Pós-graduanda & HC & 35 anos \\
\hline
\end{tabular}

O local para a realização das entrevistas foi o campus de lotação do entrevistado, sendo o campus Umuarama e Santa Mônica, pela facilidade de acesso ao público pertencente aos dois grupos e pela amplitude de relatos dos funcionários obtidos devido à diversidade de cursos ofertados. O delineamento da pesquisa não buscou uma amostra representativa que visasse a generalização neste momento, mas a "exploração das minúcias que compõem as representações, buscando na particularidade dos dados a validade dos resultados obtidos" (DINIZ, CARRIERI e BARROS, 2013, p.24).

\section{RESULTADOS}

\subsection{O Campo de pesquisa}

No caso da Universidade Federal de Uberlândia, o REUNI trouxe recursos que possibilitou o desenvolvimento de um plano de expansão entre os períodos de 2008-2012, cujos resultados foram: o aumento do número de vagas, o aumento da oferta de cursos, o aumento do número de docentes e técnicos administrativos, a expansão do campus para outras cidades mineiras e o maior número de conclusão de curso por parte dos discentes. Dentre essas consequências causadas pela expansão, está a elevação da quantidade de técnicos-administrativos no quadro de recursos humanos.

o foco deste trabalho está na figura do técnico administrativo em educação. 
Tabela 1. Impactos Globais (expectativas de transformação da Universidade ao final do Programa)

\begin{tabular}{|c|c|c|}
\hline UFU ATUAL (2007) & PLANO DE EXPANSÃO (2008-2012) & UFU FUTURA (2012) \\
\hline $\begin{array}{l}\text { No. Vagas anuais na Graduação: } \\
2.910\end{array}$ & No. Vagas anuais na Graduação: 1.350 (+ 46,4\%) & $\begin{array}{l}\text { No. Vagas anuais na Graduação: } \\
4.260\end{array}$ \\
\hline $\begin{array}{l}\text { No. Vagas anuais na Graduação } \\
\text { no Noturno: } 920\end{array}$ & $\begin{array}{l}\text { No. Vagas anuais na Graduação no Noturno: } 310(+ \\
33,7 \%)\end{array}$ & $\begin{array}{l}\text { No. Vagas anuais na Graduação } \\
\text { no Noturno: } 1.230\end{array}$ \\
\hline No. Cursos de graduação: 57 & $\begin{array}{l}\text { No. Cursos de Graduação: } 22 \text { (+ 38,5\%) Turnos Novos: } \\
5 \text { Cursos Novos: } 17 \text { Expansão Vagas: } 09\end{array}$ & No. Cursos de Graduação: 79 \\
\hline $\begin{array}{l}\text { No. Cursos de graduação no } \\
\text { Noturno: } 19\end{array}$ & No. Cursos de graduação no Noturno: $6(+31,6 \%)$ & $\begin{array}{l}\text { No. Cursos de graduação no No- } \\
\text { turno: } 25\end{array}$ \\
\hline $\begin{array}{l}\text { Relação Aluno/Professor (RAP): } \\
14,67\end{array}$ & Relação Aluno/Professor (RAP): 19,56 & $\begin{array}{l}\text { Relação Aluno/Professor (RAP): } \\
15,41\end{array}$ \\
\hline $\begin{array}{l}\text { Taxa de Conclusão da Gradu- } \\
\text { ação (TCG): } 98 \%\end{array}$ & Taxa de Conclusão da Graduação (TCG): 90\% & $\begin{array}{l}\text { Taxa de Conclusão da Graduação } \\
\text { (TCG): } 94 \%\end{array}$ \\
\hline
\end{tabular}

Fonte: UFU (2014)

Além dessas mudanças estruturais e do seu corpo de funcionários, ao considerar que a Universidade Federal de Uberlândia completou 35 anos no ano de 2013, infere-se que muitos destes funcionários que começaram as suas atividades profissionais juntamente com a fundação da UFU estão em processo de aposentadoria, isto é, ou estão se aposentando ou possuem o tempo suficiente para pleitearem tal direito. Do ponto de vista legal, à medida em que isso ocorre, é gerada vacância do cargo público, o que permite ao órgão realizar novo concurso público para provimento dessa vaga (Lei 8112/90). Essa informação é confirmada ao se fazer o cruzamento de dados disponíveis no anuário de 2013 e ilustrados na tabela abaixo.

Tabela 2. Servidores Técnicos Administrativos

\begin{tabular}{|c|c|c|c|c|}
\hline Descrição & 2009 & 2010 & 2011 & 2012 \\
\hline Técnico-administrativo - ativo permanente & 3.145 & 3.089 & 3.265 & 3.215 \\
\hline Aposentadorias concedidas & 139 & 160 & 190 & 140 \\
\hline Descrição & 2010 & 2011 & 2012 & 2013 \\
\hline Aposentadorias previstas & 537 & 566 & 515 & 562 \\
\hline Descrição & \multicolumn{4}{|c|}{2012} \\
\hline Aposentadorias previstas & \multicolumn{4}{|c|}{515} \\
\hline Concessão de aposentadoria & \multicolumn{4}{|c|}{140} \\
\hline Previsão de aposentadoria para 2013 & \multicolumn{4}{|c|}{562} \\
\hline Ingressante & \multicolumn{4}{|c|}{270} \\
\hline
\end{tabular}

Fonte: Diretoria de Administração de Pessoal. Modificada pelo autor.

Percebe-se que apesar da previsão crescente do número de TAE que podem se aposentar, o número de aposentadorias que se efetiva é relativamente baixo, ou seja, apesar de terem adquirido o direito, ainda estão em atividade. Além disso, nota-se o aumento do quadro funcional ao longo do tempo quando é feita a análise do espaço temporal entre 2009 e 2012. 


\subsection{As representações sociais dos TAEs}

A partir da análise das entrevistas, foi possível apreender tanto aspectos relevantes em relação à visão dos dois grupos estudados. De maneira geral, percebeu-se uma maior valorização da figura do "novato" por parte dos "veteranos" e uma desvalorização da representação do "veterano" na maior parte dos aspectos analisados.

Em relação ao elemento disciplina por exemplo, os entrevistados explicitaram a visão de que os "recém-ingressantes" na Universidade Federal de Uberlândia aceitam melhor a hierarquia funcional e imposições de novas regras e normas enquanto os "veteranos" possuem uma maior dificuldade nesta aceitação. Tais situações são percebidas nos trechos transcritos abaixo:

Então, em relação à disciplina, eu acho que deixa um pouquinho a desejar (risos). Principalmente, as vezes pelo fato de eles [veteranos] já terem assim, sei lá, fixado as raízes, terem alguns hábitos, tem uma certa dificuldade, bloqueio em aceitar algumas imposições novas (E01).

A função dele enquanto servidor público. "Tá" certo. O meu entendimento do servidor veterano é que ele não preza muito por boa parte das atribuições que eles têm. Acredito que principalmente pela motivação. Ele está em final de carreira e sente que o cargo que ele ocupa perdeu a importância que tinha a longo do tempo, por questões salariais. Enfim, que boa parte por se sentirem desmotivados acabam também não cumprindo com normas que um novato tentaria se esforçar a cumprir (E02).

Para os entrevistados do grupo novatos, os veteranos já não têm a disciplina na execução das suas atribuições e, também, estão desmotivados. Para os veteranos, os novatos são mais comprometidos com as atividades, têm mais atenção e, ainda, os veteranos veem o trabalho na universidade como uma oportunidade.

Essas pessoas que estão entrando agora eu vejo assim: que eles estão mais comprometidos, que estão mais assim...têm mais atenção...eles estão tentando fazer o melhor deles e também assim, eles estão aproveitando a oportunidade que estão tendo (E07).

Destacam-se os trechos a seguir, os quais tratam da disciplina em relação ao cumprimento de horário, presença no local de trabalho e assiduidade e nota-se que as opiniões entre os "veteranos" estão divididas, mas a dos "novatos" é praticamente unânime em dizer que os veteranos não cumprem os horários de trabalho de maneira adequada.

Eu vejo como companheiros de trabalho. A maioria (dos novatos) não cumpre o horário de trabalho porque há uma maior liberdade na questão de horário, são mais abertos e livres. Não existe mais aquela pressão por parte dos chefes (E05).

Eu acho que eles (os novatos) cumprem melhor do que quem está aqui há muito tempo (Eu tiro por mim, porque eu nunca chego no horário) (E07)

Para os novatos, os veteranos não são assíduos e não têm compromisso com o trabalho. $\mathrm{E}$, ainda, consideram que os novatos são assíduos em virtude das possibilidades de serem aplicadas penalidades. Já os veteranos não têm mais medo de qualquer represália.

Agora em relação à assiduidade eles [os veteranos] pecam. Tipo assim, não tem mais todo aquele comprometimento. Às vezes aquele que está chegando agora, até por medo de alguma sanção, ele tende a ser mais assíduo "né", chegar nos horários e "tals" enquanto o veterano peca nesse sentido de assiduidade (E03).

Eu diria que todo mundo cumpre presença física no local de trabalho, mas assim...cumprimento de horário, cumprimento da carga horária semanal, realmente deixa a desejar, ela não é bem cumprida. Realmente ela não é cumprida, mesmo porque acredito que quem 
pertence a esse grupo de veteranos, perderam qualquer medo, qualquer receio de alguma represália por parte de algum superior hierárquico (E02).

Em relação ao elemento iniciativa, a percepção tanto dos "novatos" quanto à dos "veteranos" é a de que os técnicos administrativos possuem disposição a colaborar e executar as tarefas cotidianas. Porém nota-se um esforço maior por parte dos mais jovens em aprimorar o seu trabalho.

\begin{abstract}
À iniciativa, essa questão de disposição para colaborar eles têm, tanto que eles [veteranos] estão aqui pra isso inclusive, porque de fato se eles não quisessem mais estar na universidade, eles já teriam prazo para...teriam abandonado aqui.Então essa questão eu acho positiva. Eles têm disposição em ajudar o outro, inclusive até para passar os seus conhecimentos e inclusive a gente precisa muito disso, a gente que está chegando agora (E01).
\end{abstract}

Para os veteranos, os novatos têm mais iniciativa do que eles mesmos.

E assim, eles [novatos] têm comprometimento, tentam mudar sabe [...]As coisas que já estão assim bem defasadas no setor, mudar rotina.Isso eu acho importante. Eles têm mais iniciativas porque estão mais novos, porque "nós" [veteranos] estamos acostumados a tudo (E07).

Eu ainda continuo vendo que o jovem é como todo servidor público: ele trabalha, é assíduo, cumpre os horários, tem determinação, etc (E06).

No que diz respeito à responsabilidade, a percepção foi a de que ambos os grupos a confundem alguns atributos pertencentes à categoria disciplina, porém ao elencar o que diz respeito a esse indutor, os entrevistados disseram que existe um zelo pelo patrimônio público e um deles em tom de ironia chegou a dizer que "o zelo é tão grande que as pessoas acham que as mesas, computadores e salas são delas (risos) (E3) ". No caso do cumprimento dos prazos, houve novamente uma imagem negativa dos veteranos e em relação aos novatos, a opinião ficou dividida. Para os veteranos, os novatos comportam-se com maior cuidado por temerem o a avaliação do período de estágio probatório. Quanto aos cuidados com informações, valores ou pessoas, não houve manifestação.

Eles [novatos] têm mais iniciativas porque estão mais novos, porque "nós" estamos acostumados a tudo e por isso deixamos pra última hora; e eles não. Cumprem tudo dentro do prazo estipulado (E07).

Eu acho que todos cuidam do patrimônio de maneira igual[...] Os mais velhos deixam tudo pra última hora, mas sempre dão um jeitinho. Já os mais novos fazem antes porque estão no estágio probatório. (E08)

Por fim, ao falarem sobre a produtividade, ficou claro que a visão dos jovens é a de que o veterano continua produzindo, porém menos do que eles, ou seja, não agregam tanto valor à Universidade assim como antigamente. Apesar disso, os veteranos pensam que a maioria produz, e um dos participantes entende que os novatos receiam não serem aprovados no estágio probatório, o que gerou a reflexão: quando os novatos forem aprovados no estágio probatório, continuarão a ter esses mesmos comportamentos? Seguem os trechos que retratam esses momentos das entrevistas:

Ah, eles produzem aquilo que tem que fazer e pronto. Deu o horário de trabalho ou a tarefa ficou pronta, eles param por aí. (E4).

Em relação à produtividade, é baixa principalmente pela questão da motivação mesmo. Pessoas no final de carreira que não têm mais onde crescer, então não se sentem motivados nem a progredir na carreira nem a serem mais produtivos (E2). 
Olha, eu acho que são produtivos mais ou menos, pois como assim já estão cansados da rotina, do trabalho, de alguma coisa assim, eles têm o conhecimento e a capacidade de exercer algumas coisas, mas não tem mais aquela disposição. Então eles produzem, mas nem tanto (E1).

Tem muitos que já querem produzir, mostrar serviço para tentar crescer e outros não, só fazem um pouco e só para passar no estágio probatório (E06).

E eu creio que essa nova geração seja tão aguerrida como nós somos, porque a partir do momento que presta o concurso para universidade mesmo que seja para posteriormente prestar outro concurso melhor em determinado órgão federal que o ganho é maior que no poder executivo. (E05).

De modo geral, os entrevistados manifestaram suas representações sobre a atuação de novatos e veteranos na universidade. Outro fato que se nota no discurso dos novatos é o de que todos os quatro entrevistados deste grupo tentaram, em quase todos elementos norteadores questionados, fazer uma certa comparação em relação a eles mesmos, enaltecendo a sua figura como sendo "melhor". Ao contrário, três dos entrevistados do grupo veteranos limitaram-se mais a falar sobre os que foram arguidos e no momento em que comparavam, as representações que eles reproduziam sobre si mesmos não era tão positiva, principalmente relativos à assiduidade e cumprimento de horário.

Segundo a ótica de representação social adotada, Moscovici (1978) entende que há uma complementariedade entre o social e o individual. Segundo o autor, os indivíduos ao estabelecerem este diálogo entre as duas esferas, constroem suas próprias representações e comunicam essas aos demais indivíduos, de forma que fomenta-se um ciclo que retroalimenta continuamente. Essas representações não são criadas pelo indivíduo de maneira isolada, mas sim devido à comunicações e cooperação dos grupos. As representações assim passam a circular como se tivessem vida própria e ao se interagirem abrem espaço para o surgimento de novas representações e o desaparecimento de outras mais antigas.

Aseguir, apresentamos um quadro com uma síntese das representações dos entrevistados:

Quadro 1 - Representações sociais dos entrevistados

\begin{tabular}{|l|l|l|}
\hline \multicolumn{1}{|c|}{ Categorias } & RS dos veteranos sobre os novatos & \multicolumn{1}{|c|}{ RS dos novatos sobre os veteranos } \\
\hline Disciplina & $\begin{array}{l}\text { Mais comprometidos, mais aten- } \\
\text { ção, aproveitam a oportunidade }\end{array}$ & $\begin{array}{l}\text { Rejeitam imposições novas } \\
\text { não preza muito por boa parte das atri- } \\
\text { buições } \\
\text { demotivados }\end{array}$ \\
\hline Iniciativa & $\begin{array}{l}\text { Tem iniciativa, determinação, com- } \\
\text { prometimento }\end{array}$ & Disposição para colaborar \\
\hline Responsabilidade & $\begin{array}{l}\text { Cumprem com os prazos, cuidam } \\
\text { do patrimônio }\end{array}$ & Têm zelo com o patrimônio \\
\hline Produtividade & $\begin{array}{l}\text { Hoje fazem o que têm que fazer, } \\
\text { mas com o tempo vão se acomodar }\end{array}$ & $\begin{array}{l}\text { Produzem pouco, falta disposição, es- } \\
\text { tão acomodados }\end{array}$ \\
\hline Assiduidade & $\begin{array}{l}\text { Não cumprem horário, porque não } \\
\text { há cobrança } \\
\text { Cumprem horário }\end{array}$ & Não cumprem horário de trabalho \\
\hline
\end{tabular}

Fonte: dados da pesquisa

As representações dos entrevistados refletem o grupo social ao qual pertencem (JOCVHCELOVITCH, 1995), ou seja, os novatos têm maior compromisso e responsabilidade 
no trabalho do que os veteranos, isso, em grande parte, por estarem em um período de avaliação. Como Moscovici (1978) afirma, a representação social, além de permitir a compreensão do mundo, orienta o comportamento. Nesse sentido, as representações sociais de técnicos-administrativos veteranos e novatos construídas pelos entrevistados podem conduzi-los a comportamentos que, por sua vez, criam a realidade organizacional, trazendo impactos para as interações cotidianas.

\section{CONSIDERAÇÕES FINAIS}

Neste trabalho tivemos por objetivo descrever e analisar as representações sociais construídas de dois grupos: os que ingressaram à Universidade e estão em atividade por no máximo 3 anos - ou seja, em estágio probatório; e aqueles cujo tempo de serviço os permitem o direito de aposentar-se. Para chegar ao objetivo descrito, utilizou-se a Teoria das Representações Sociais, no contexto da psicologia social. Os métodos de coleta e análise das informações pautaram-se na evocação livre e na análise do discurso.

Desta maneira, espera-se que este trabalho tenha contribuído para a compreensão de aspectos relevantes da dinâmica social da Universidade Federal de Uberlândia, no que diz respeito às representações sociais dos técnicos-administrativos quanto aos aspectos disciplina, iniciativa, responsabilidade, produtividade, assiduidade. Os resultados podem servir de orientação para os gestores de pessoas no desenvolvimento de ações e políticas relacionadas a esses aspectos.

Como limitação deste trabalho, apontamos que, pelo fato de constituir-se em uma pesquisa realizada em um contexto específico, não permite uma generalização dos resultados. Como proposta de novas contribuições ao tema estudado, sugere-se estudar as representações sociais atuais e históricas, em termos comparativos, uma vez que, como evidenciado na contextualização deste trabalho, a Universidade está passando por um momento de renovação e os grupos estão frequentemente se modificando, o que poderia ensejar novas representações.

\section{REFERÊNCIAS}

ANDRADE, M. M. Como preparar trabalhos para cursos de pós-graduação: noções práticas. 4. Ed. São Paulo: Atlas, 2001.

ANDRIOLA, B. W.; SOUZA, L. A. de. Representações Sociais dos Gestores e dos Técnicos das Unidades Acadêmicas Da Universidade Federal Do Ceará (Ufc) Acerca da Autoavaliação Institucional. Avaliação, v. 15, n. 2, p. 45-72, 2010.

BARDIN, L. Análise de conteúdo. Lisboa: Edições 70, 1979.

BRASIL. Constituição (1988). Constituição da República Federativa do BRASIL. Capítulo da Saúde, Brasília, 1988.

BRASIL. Decreto $n^{\circ}$ 5.707. Política Nacional de Desenvolvimento de Pessoal. Diário Oficial da União, Brasília, 26 de fevereiro de 2006.

BRASIL. Lei $n^{\circ}$ 8.112. Dispõe sobre o regime jurídico dos servidores públicos civis da União, das autarquias e das fundações públicas federais. Diário Oficial da União, Brasília, 11 de dezembro de 1990.

CAVEDON, N. R.; FERRAZ, D. L. Representações sociais e estratégia em pequenos comércios. RAE - eletrônica. São Paulo. Vol. 4, n. 1 (jan./jun. 2005), p.1-18 
CORDEIRO, C. J.A. Avaliação de desempenho dos servidores técnico-administrativos da UFPE: um estudo sobre representações sociais. 2013. 190f. Dissertação (Mestrado em Gestão Pública para o Desenvolvimento do Nordeste. Universidade Federal de Pernambuco, Recife, 2013.

CORREA, A. M. H. et al. Soldadinhos-de-chumbo e bonecas: representações sociais do masculino e feminino em jornais de empresas. Rev. adm. contemp. [online]. 2007, vol.11, n.2, pp. 191-211.

DINIZ, A. P.; CARRIERI, A. P.; BARROS, A. N. Invisibilidade social e trabalho noturno: reflexões a partir de representações sociais de garçons. Gestão e Planejamento, vol. 14, n.1, 2013.

DUARTE, M. T.; FERREIRA, S. A.; LOPES, S. P. Gestão por competências como ferramenta para o desenvolvimento dos servidores técnico-administrativos: case da Universidade Federal do Tocantins. Administração Pública e Gestão Social. V. 1, n.2, 2009.

FIGUEIREDO, M. D.; CAVEDON, N. R. O espaço dos indesejáveis. A circularidade da representação de estigma em um centro comercial de Porto Alegre. Civitas, vol. 12, n. 3, 2012.

GARCIA, R. W. D. Representações sociais da alimentação e saúde e suas repercurssões no comportamento alimentar. Revista de Saúde Coletiva.[online]. 1997, vol. 7, n.2, PP.51-68.

GOMES, A. M. T; OLIVEIRA, D. C. A auto e heteroimagem profissional do enfermeiro em saúde pública: um estudo de representações sociais. Rev Latino-am Enfermagem. [online]. 2005, vol.13,n.6, pp.1011-1018.

GUSTAVSSON, E.; CZARNIAWSKA, B. Web Woman: The On-line Construction of Corporate and Gender Images. Organization, v. 11, 2004.

KAMPF, Cristiane.Ensino superior no Brasil: breve histórico, mudanças e tendências atuais. 2013. Disponível em < http://www.univesp.ensinosuperior.sp.gov.br/preunivesp/5312/ ensino-superior-no-brasil-breve-hist-rico-mudan-as-e-tend-ncias-atuais.html >. Acesso em 16/07/2014.

MARQUES, S. C., OLIVEIRA, Denize C., GOMES, Antonio Marcos Tosoli. AIDS e representações sociais: uma análise comparativa entre subgrupos de trabalhadores. Rev. Psicologia teoria e prática. [online]. 2004, vol.6, pp. 91-104.

MEC.O que é o REUNI. Disponível em: < http://reuni.mec.gov.br/o-que-e-o-reuni >. Acesso em: 31/06/2014.

MOSCOVICI, S. A representação social da psicanálise. Rio de Janeiro: Jorge Zahar, 1978.

PROREH. Resolução do CONDIR sobre o estágio probatório na UFU. Disponível em < http://www.proreh.ufu.br/node/23 > . Acesso em 06/07/2014.

PROREH. I Encontro de Servidores da Universidade Federal de Uberlândia: desafios e perspectivas. Disponível em < http://www.proreh.ufu.br/encontrodeservidores $>$. Acesso em 07/07/2014.

PULLEN, A.; RHODES, C. Parody, subversion and the politics of gender at work: the case of Futurama's 'Raging Bender'. Organization, v. 20, pp. 512-533, 2013.

UFU. Plano de Expansão da UFU 2008-2012. Disponível em < http://www0.ufu.br/ 
expansaoufu/24.php >. Acesso em 31/06/2014.

UFU. Anuário 2013 - Ano Base 2012. Disponível em < http://www.ufu.br/pagina/anuario2013-ano-base-2012 >. Acesso em 07/07/2014.

SALLES, D. M.; COSTA, I. S. A. Representações Do Trabalho: Estudo Sobre Confinamento Na Indústria Petrolífera. Revista de Administração de Empresas, V. 53, 2013.

SPINK, M. J. P.. O conceito de representação social na abordagem psicossocial. Cad. Saúde Pública [online]. 1993, vol.9, n.3, pp. 300-308. 